\title{
Managing Occupational Health And Safety In A Ghanaian Building Industry (A Case Study Of Some Construction Sites of Eris Property Group In Accra)
}

\author{
Dolores Mensah Hervie \\ Department of Secretaryship and Management Studies, \\ Accra Technical University, P. O. Box GP 561, Accra-Ghana \\ Cynthia Oduro-Nyarko \\ Department of Secretaryship and Management Studies, \\ Accra Technical University, P. O. Box GP 561, Accra-Ghana
}

\begin{abstract}
Achieving occupational health and minimisation to a large extent possible hazard to health and safety in the construction industry is the responsibility of all employees. The onus is on management to achieve high standards in such matters as required by the constitution of Ghana (1992) and the Labour Act 2003 (Act 651) in relation to health and safety at the work place. It is high time construction practitioners pay much attention to health and safety issues on sites and implement policies or framework in this regard. The main objective of this study is to find out if contractors and developers in the building industry have health and safety policies and whether these policies are implemented and functional. Through questionnaires, interviews and literature, it was revealed that majority sites have employees' orientation on health and safety before starting work. More so, management and employees have regular interactions to continuously re-orient the mind on importance of site safety. It also came to light that local contractors are guiltier when it comes to site health and safety practices. Based on the findings from this research, it was recommended that a regulatory body should be formed for the building industry. This body should develop an institutional health and safety framework in line with the constitution and the Labour Act of Ghana that would be stringently implemented in Ghanaian construction sites. Furthermore, international construction sites normally have dedicated department which are well resourced to ensure health and safety measures which local contractors could emulate.
\end{abstract}

Key words: Health, Safety, Occupational, Construction sites, OHS Policies

\section{INTRODUCTION}

In recent years, occupational health and safety at a workplace has received much attention from both employers and employees. The building industry is not excluded in this move. The Ghana Labour Act 2003 (Act 651) indicates that it is the duty of an employer to ensure that their employees work under satisfactory, safe and healthy conditions. (Section 118) of the mentioned Act 2003(Act 651) specifically, sets out the key duties, responsibilities and administrative measures to be taken by employers to avoid risks, injuries, casualties and unsafe working environment. The constitution of Ghana (1992 - Article 24 (1) also demands that all persons working in both formal and informal sectors of the economy be protected by ensuring that they work under safe conditions devoid of any adverse effect on their health. Alli (2008), stated that Occupational health and safety as the science of the anticipation, recognition, evaluation and control of hazards arising in or from the workplace that could impair the health and well-being of workers, considering the possible impact on the surrounding communities and the general environment. 
According to International Labour Organization (ILO, 2003b) report an estimated 2 million occupational fatalities occurred across the world in 2003 and the highest of these deaths was caused by work related cancers, circulatory and cerebrovascular diseases and some infectious diseases. The overall annual rate of occupational accidents, fatal and non-fatal, is estimated at 270 million Hämäläinen, Takala and Saarela (2006).

Studies conducted in Ghana on occupational health and safety particularly on construction sites revealed a poor state of health and safety on Ghanaian construction sites (Samuel Laryea, 2016). According to this researcher, the primary reasons for the state of health and safety on construction sites were lack of strong institutional framework governing construction activities and poor enforcement of health and safety policies as well as procedures.

Construction sites are expected to be well organized by tiding up the sites, have a decent welfare, health and safety policy document that would ensure that workers have the requisite personal protective equipment (PPE) to work with, providing well protected plant and equipment in safe work activities, ensuring quick response and investigation into all incidents, accidents and near misses in an attempt to minimize recurrences and also, take other measures to prevent risks and hazards. They are again expected to train their supervisors and workers to be health and safety conscious. The personal protective equipment (PPEs) at a construction site should include: reflectors, safety boots, helmets, overalls, nose masks, goggles etc.

This study was conducted on Eris Property Group (international property developers) construction sites in the Greater Accra Region (335 Place and SU Tower). Eris Property Group is a fully integrated property development and services group which provides a range of commercial property skills in South and sub-Saharan Africa markets. Eris had engaged the services of De-simone Ltd (the main construction company)., Pernium Ghana Ltd. (Health and Safety Consultants on sites), the rest are: K3 Aluproducts Ltd., Elisones Ltd., Sylprin Fire \& Solar Co., Jeffdaz Painting Ltd, VACC Technical Services Ghana Ltd., Lambert Electromec Ltd. (subcontractors engaged by Desimone) working on the two construction sites. Eris, had engaged the services of Pernium Ghana Ltd; occupational health and safety consultants to ensure health and safety policy and standards were adhered to on the sites. These sites were chosen for the study to ascertain the extent to which international contractors operating in the Ghanaian building industry consciously adhered to occupational health and safety laws, standards, regulations and practices. More so, whether the workers were aware of their responsibilities and obligations as far as their health and safety are concerned. Hence the main purpose of this is to find out whether there is occupational Health and Safety (OHS) Policy available in the building industry, whether it is being used and to recommend ways that could be applied to prevent or minimize accidents and occupational hazards in the said industry.

Unlike advanced countries where there are statutory and legal framework for construction workers on construction sites that sought to minimize risks and work hazards, for instance, (The Construction Regulations 2007 (S.I. 2007/No. 320) in the United Kingdom, there are no such stringent occupational health and safety framework as far as construction industry in Ghana is concerned. As a result, most construction companies do not have health and safety policy, officer, standards or principles to guide their activities. Those who have, pay less attention to it when it comes to working on sites. The loss from work-related incidence, accidents, injuries and other risks could be estimated in terms of death, loss of skilled labour, hospital bills, high insurance premium payments, replacement cost of plant and equipment. There is also lack of proper accident investigation/data and therefore, a lack of institutional learning. 


\section{LITERATURE REVIEW}

The need for physical and emotional security of employees demands equal attention. Employers are required by the labour law to provide working conditions that do not impair the safety or health of their employees. Employers must ensure a work environment that protects employees from physical hazards, unhealthy conditions, and unsafe acts of other personnel. Through effective health and safety programmes, the physical and emotional well-being, as well as the economic security of employees may be preserved and boost employee performance.

Construction companies must maintain working conditions in which employees are not only safe but also feel safe. Health and safety programmes deal with the prevention of accidents and with minimizing the resulting loss and damage to persons and property. Employees relate more to systems of work than the working environment, but both health and safety programmes are concerned with protection against hazards Armstrong (2007). According to Megginson et al. (2002), employee health and safety also depends on the size of the organization, the type of industries, and the type of occupation involved. With the building industry, the importance of healthy and safe policies and practices is often underestimated by those concerned with managing construction sites and by individual managers/supervisors. It must be noted that the prevention of accidents and elimination of health and safety hazards are a prime responsibility of managers to minimize suffering and loss.

In Ghana the realization of the importance of health and safety laws have been passed to strengthen health and safety. Labour Regulations 1969 (L1 632), Factories, Offices and Shops Act, 1970 (Act 328) amended by PNDC Law 66, and Workmen Compensation Law, 1987 (PNDCL 187). While the laws safeguarding employees' physical and emotional well-being are incentives, many organizations are motivated to provide desirable working conditions by virtue of their sensitivity to human needs and rights. The most cost-oriented employer recognizes the importance of avoiding accidents and illness wherever possible. Cost associated with sick leave, disability payments, replacement of employees who are injured or killed, workers' compensation far exceed the costs of maintaining health and safety programme.

Since accidents and illnesses attributable to the work place may also have pronounced effects on employee morale and on the goodwill that the organization enjoys in the community and in the country as a whole, employers should provide safety training for their employees. It is important to encourage and follow up on employee compliance to safety regulations, precautions, and discipline employees for noncompliance. In this case, management must be concerned about the protection of the organization's employees from hazards at work and to indicate how this protection will be provided. Casio (1995) indicates that management's first duty is to formulate a safety policy. Its second duty is to implement and sustain this policy through control programmes and stressed that such programmes have four components. A safety budget, safety records managements, personal concern and management's good example. Most construction in Ghana lack such health and safety policies that guides and boast employees' morale for higher performance. Some of them have no written health and safety policies required to demonstrate that management is concerned about the protection of the firm's employees from hazards at work and how these protections would be provided. The Study indicates a close relationship exists between safety and employees' satisfaction with their work. It further proved that where top management actively supports safety programmes, the accident frequency and severity rates are lower Megginson et al (2002). The aim of this research is to collect data to find out whether the construction sites in the study area have any health and safety policies support for their employees as well as, management support to fully implement these policies. 


\section{METHODS AND ANALYSIS}

The descriptive survey research design was used for the study. Descriptive survey is a process of collecting data in order to answer questions concerning the current status of the subject in the study Mugenda and Mugenda (2003). The target population of this study was the employees and management of the multinational construction firms and the developer (ERIS Developer. Desimone and other sub-contractors) in Ghana. The total population of employees and contract staff of the two construction firms were about two hundred (200) as at the time of data collection.

\section{Determining the Sample Size}

Based on the random sampling method of sample size determination for a finite population, the study made used of approximately one-hundred employees from Desimone and the other subcontractors. These figures are considered appropriate sample size for the study because it is in conformity with the Hair et al (2010) table of sample size determination of continuous and categorical data.

\section{Method of Data Collection}

Data was collected using structured questionnaire (instrument for data collection), this was used to collect relevant data from all sources types. The questionnaire was (was organized in two portions) one for the management of sites and the other for (for junior staff). Follow up interviews were also conducted.

\section{Data Analysis}

Quantitative analysis (was used as a tool to analyze data obtained) applying descriptive statistics techniques such as the mean, median and the standard deviation to describe the responses provided by the respondents. Inferential statistical technique such as the ChiSquare test $\left(\chi^{2}\right)$ was used to examined association between nominal variables. SPSS (version 25 ) was used for the analysis of data. The results were presented using tables and frequency.

\section{a. Demographic profile of the respondents}

\section{RESULTS AND DISCUSSIONS}

This study considered one-hundred (100) respondents, of which eighty-five (85) were active respondents who were able to complete the questionnaire assigned them. This constituted about $85 \%$ of coverage; the remaining respondents did not provide any response at all to the researcher. The result in table 1 below depicts the demographic profile of the respondents. From the result as shown in the table 1,91.8\% (78) of the respondents were males and the remaining $8.2 \%$ (7) were female. This value shows that the construction industry in Ghana receives or welcomes few females in its setup this could be as a result of the nature of the work. Also, the ages of the respondents were obtained, from the analysis there is an evident that majority of the respondents were within the age group of 20-29years. This age group constituted about $49.4 \%$ (42) of the total respondents, followed by those within the age group 30 -39years forming about 32.9\% (28). This is an indication that the nature of the work requires strength and this kind of strength could only be obtained among those in their youthful age. Furthermore, the study obtained information about the work experience of the respondents especially the number of years that they had worked within the construction industry. It was realized that majority of the respondents had worked in the construction industry between 6 months to 1 year when they joined the industry. They constitute 32.9\% representing 28 of the respondents. Some of the employees on site said they had worked in the industry for more than two years which has helped them gained a lot of experiences, they formed about $23.5 \%$ indicating 19 respondents. This was followed by those who said they had worked in the construction industry from 1 year to 2 years, $22.4 \%$ (19) of the respondents had 
worked within these years. $21.2 \%$ (18) of the respondents made it known that they had worked for less than 6 months in the industry.

Table 1: Demographic profile of respondents

\begin{tabular}{llcc}
\hline Variable & Level & $\mathbf{N}$ & $\mathbf{\%}$ \\
\hline Sex of respondents & Male & 78 & 91.8 \\
& Female & 7 & 8.2 \\
& Total & $\mathbf{8 5}$ & $\mathbf{1 0 0 . 0}$ \\
Age & $20-29$ years & 42 & 49.4 \\
& $30-39$ years & 28 & 32.9 \\
& $40-49$ & 6 & 7.1 \\
Work experience & Above 50 years & 9 & 10.6 \\
& Total & $\mathbf{8 5}$ & $\mathbf{1 0 0 . 0}$ \\
& <6 months & 18 & 21.2 \\
& 6 months-1yr & 20 & 32.9 \\
& 1yr-2yrs & 19 & 22.4 \\
& Above 2 years & 28 & 23.5 \\
& Total & $\mathbf{8 5}$ & $\mathbf{1 0 0 . 0}$ \\
\hline
\end{tabular}

\section{b. Exploring respondents' knowledge on Occupational Health and Safety (OHS) at the workplace.}

Knowing respondents view on the subject matter was one of the objectives that was formulated by the researchers. The result as shown in the table below indicates that, most of the respondents had been given orientation on the OHS when they were employed. About $96.50 \%(82)$ of the total respondents said yes to the question asked whether they were given orientation on OHS. A few of the respondents claimed that they did not receive their orientation as indicated in the table, $2.4 \%$ (2) and only one person did not provide any response to the question. The responses show that employees go through orientation before commencement of their jobs.

Also, respondents were asked whether if OHS was useful to them as employee, $91.1 \%$ (80) said that OHS is useful to them whereas 5.9\% (5) did not provide any response to the question asked.

Furthermore, it was realized that respondents met twice in a month to discuss issues relating to OHS among others as indicated by $34.10 \%$ (29). Those who claimed they met daily and 4 times in a month were $22.40 \%$ (19) each, whereas $16.5 \%$ (14) were of the view that, they met once a month to learn about occupational health and safety related issues. Few respondents did not provide any response to the question asked, they represent $4.8 \%$ (4). Meaning, OHS is useful at both sites.

Majority of the respondents were interested in attending health and safety meeting, the result shows that $92.9 \%$ (79) said yes, they wished to attend such meeting, whereas 5.9\% (5) said they were not interested in such meetings. 97.6\% (83) of the respondents said they wished or were interested in the safety meetings and would implement the safety lessons learnt on site, whereas $2.4 \%$ (2) did not provide response to the question. 
Table 2

\begin{tabular}{llcc}
\hline Variable & Level & $\mathbf{N}$ & $\mathbf{\%}$ \\
\hline $\begin{array}{l}\text { Did you get orientation on OHS } \\
\text { since you were employed? }\end{array}$ & Yes & 82 & 96.5 \\
& No & 2 & 2.4 \\
Is it useful to have OHS & No response & 1 & 1.2 \\
& Yes & 80 & 94.1 \\
& No response & 5 & 5.9 \\
Safety tool box meeting & Twice & 29 & 34.1 \\
& Daily & 19 & 22.4 \\
& 4 times & 19 & 22.4 \\
& Once & 14 & 16.5 \\
Are you interested in attending? & No response & 4 & 4.8 \\
health/safety meetings & & & \\
& Yes & 79 & 92.9 \\
Do you easily implement safety? & No & 5 & 5.9 \\
lessons at your work? & No response & 1 & 1.2 \\
& Yes & 83 & 97.6 \\
\hline
\end{tabular}

\section{c. Provision of personal protective equipment}

The result below indicates the responses provided by the respondents on whether they are provided with personal protective equipment as stated below in the table. Among those who said "Yes" they were been provided with personal protective equipment (PPE); 17\% (82) of them said yes, they were provided with foot protection equipment such as boot. 17.20\% (83) said they were provided with eye protection. Hand protection had a score of $17.20 \%$ (83), Helmet protection ,16.60\% (80), Respiratory equipment $17.20 \%$ (83) and the least item that received the least support was the hearing protection equipment which had a percentage score of $14.90 \%$ (72), meaning that respondents were not receiving much equipment that could be used to protect their ears (The other implication was less workers are active in areas with much noise). This means that much attention must be given to prevent those who work at the site from contracting ear related illness. In a summary, it could be said that $97.70 \%$ of the total respondents said yes, that they were provided with PPE with few individuals, about 5.3\% said No they were not given such equipment. This is an indication that majority of the respondents were of the view that the personal protection equipment was provided by the management of the construction sites (A late visit revealed that it was must for everybody to use PPE hence, a few may have misplaced theirs.)

Table 3: Respondents who said Yes, that they are provided with personal protective equipment

\begin{tabular}{llcc}
\hline & Level & $\mathbf{N}$ & $\mathbf{\%}$ \\
\hline & Foot protection & 82 & $17.00 \%$ \\
& Eye protection & 83 & $17.20 \%$ \\
& hand protection & 83 & $17.20 \%$ \\
& hearing protection & 72 & $14.90 \%$ \\
Total & respiratory & 83 & $17.20 \%$ \\
& Helmet & 80 & $16.60 \%$ \\
& & 483 & $100.00 \%$ \\
\hline
\end{tabular}




\section{d. Accident related issues at the site}

In order to determine the accident related issues of the selected building sites, respondents were asked, how often they were prone to accidents in a month. From the result obtained, $45.90 \%$ (39) of the respondents were of the view that accidents on site mostly occurred once a month, which means that measures had been put in place to prevent accidents at the construction sites. This was closely followed by those who said, accidents did not occur every month since they joined the construction sites but rather once a while, it does but not every month, this view was represented by $18.8 \%$ of the respondents indicating 16 site men. Some of the respondents made it known that accidents did occur in most cases twice, thrice and four times in a month. The result obtained indicates that cumulatively $35.20 \%$ representing 30 site men claimed that accidents occurred at least twice, three and four times in a month. from the result, it was evident that accidents in the industry is not as rampant as it used to be (in other local construction sites) since, there is the observation of strict safety and health policies in the organization. However, because, they deal with heavy equipment in most cases, once a while they experienced such cases as identified by some of the respondents.

Table 4: How often do accidents occur at site in a month

\begin{tabular}{lcc}
\hline Level & $\mathbf{N}$ & $\mathbf{\%}$ \\
\hline Once & 39 & 45.9 \\
None & 16 & 18.8 \\
Twice & 15 & 17.6 \\
Four times & 8 & 9.4 \\
Three times & 7 & 8.2 \\
Total & 85 & 100 \\
\hline
\end{tabular}

One of the key role of safety and health education on site is to be able to address injuries and accidents related issues in the course of operation, this could be enhanced if site men who either get injured or accidents are able to report such incidence to health and safety manager or personnel for the needed intervention to be done.

However, when such incidence or occurrences are not reported to the personnel in charge, measures could not be put in place to address future occurrence in the organization, as a result of that there was a crosstabulation to determine the association between how often accidence / accidents / injuries occurs and whether or not respondents would report it for further analysis. The table 5, below depicts the result obtained from the crosstabulations analysis, it revealed that, there is significance difference between the two variables, among those who said accidents or injuries did not occur and those who said Yes, they would report for further investigations were $19.85 \%$ and $9.9 \%$ respectively. From the result, respondents who claimed that accidents on site most often occurred three times a month and said yes, they would report accidence to those in charge for investigation were $6.2 \%$ (5). Also $17.3 \%$ (14) said accidents occurred twice a month and they would report incidence for an investigation.

Furthermore, among respondents who agreed that accidents occurred on the sites, 46.9\% (38) of them said accidents occur once every month and they are willing to report to health and safety manager(s) for the necessary action to be taken to prevent future occurrences. There are some respondents who claimed that they would not report accidents related issues for investigation, and from the result they seemed not to be significant as compared to those who said they would report issues for investigation. Four (4) respondents made it known that they would not report any form of injuries/ accidents as they formed less than $5 \%$ of the total responses. 
This is an indication that indeed minimal accidents occurred and respondents are willing to report it to authorities for the necessary action to be taken to prevent future occurrences. This significant difference is confirmed by the chi-square test $\chi^{2}{ }_{4}=10.603$, with small significant value ( $p$-value $=0.03$ ) less than $5 \%$ significant level, which means that there is significant difference between the occurrence of accidents or injuries on the construction sites and workers readiness to report such occurrence to health and safety officers for an investigation to avert it occurring in the near future.

Table 5: Cross tabulation between occurrences of accidents on and whether, they would be reported for further investigation

\begin{tabular}{llccc}
\hline & & \multicolumn{2}{c}{$\begin{array}{c}\text { Will you report incidence for } \\
\text { investigation? }\end{array}$} & Total \\
\cline { 3 - 3 } & & Yes & No & \\
How often do accidents & None & $19.8 \%(16)$ & 0 & 16 \\
occur on site & Four times & $9.9 \%(8)$ & 0 & 8 \\
in a month? & Three times & $6.2 \%(5)$ & $50 \%(2)$ & 7 \\
& Twice & $17.3 \%(14)$ & $25 \%(1)$ & 15 \\
& Once & $46.9 \%(38)$ & $25 \%(1)$ & 39 \\
Chi-Square $\left(\chi^{2}\right)$ value & Total & $\mathbf{8 1}$ & $\mathbf{4}$ & $\mathbf{8 5}$ \\
df & $10.603^{\text {a }}$ & & & \\
Sig-value & 4 & & \\
\hline
\end{tabular}

Though, there are significant differences in the various levels of occurrence of accidents and incidence on sites and measures put in place to prevent them, yet respondents were of the view that these areas must be given much attention to either reduce or prevent accidents related issues on sites. From the output as shown in the table 6 below, there is an indication that respondents needed much attention in the area of height and lifting of equipment. The respondents claimed that most of the work they were doing was on height and as a matter of fact they need more attention to prevent accidents or injuries on sites as it was indicated by $49.4 \%$ (42) of the total respondents. Some of the respondents made it known that attention must be given to cover all areas of the sites, not necessarily on height but all areas where accidents or injuries could occur, this was indicated by $34.1 \%$ (29) of the total respondents. Among those who wanted much attention to be given to the personal protection equipment alone were $8.2 \%$ (7) of the total respondents, whereas few were of the view that sanitation issues should be considered on sites as it was indicated by $2.4 \%$ (2) of the total respondents. $5.9 \%(5)$ of the total respondents did not give any view on what must be done.

In summary, there is an indication that majority of the respondents want much attention to be given to safety on sites especially in the area of height and lifting of machines to prevent accidents or injuries on sites based on the result obtained.

Table 6: Areas that need more attention to prevent accidents on the construction sites

\begin{tabular}{lcc}
\hline Levels & $\mathbf{N}$ & $\mathbf{\%}$ \\
\hline Working at height and lifting machines & 42 & 49.4 \\
All areas & 29 & 34.1 \\
In terms of PPEs & 7 & 8.2 \\
Sanitation & 2 & 2.4 \\
No response & 5 & 5.9 \\
Total & 85 & 100 \\
\hline
\end{tabular}




\section{e. Officers and management views of health and safety issues on site}

Management of the site were not left out of the study. They were asked series of questions on their views on health and safety related issues on site. Eight (8) staff of the management level were contacted and from the responses they provided, they indicated that one of their priority on sites is health and safety, they put measures in place to curtail incidence/ accidents and injuries on both sites where the surveys were conducted by providing personal protection equipment to guard them against any occurrences, having initial training upon employment and organizing regular health and safety meetings. They agreed that at times accidents do occurs, but it occurs once in a while. They claimed that some of the frequent occurring incidence that affected employees in most cases were dust which enters their noise and eyes, burns and bruises, loose materials falling from heights and chemical spoilages.

They also claimed that the OHS unit conducted periodic inspection on site to avoid accidents on site. They made it known that inspections are key to their services and not taken for granted. They said inspection is conducted almost every day of the month, in order to prevent accidents or injuries on sites.

\section{CONCLUSION AND RECOMMENDATION}

On health and safety, the study (considering the 2 sites) found that managers in the building construction industry were aware of the health and safety regulations regarding the nature of their work. They also had health and safety policy put in place for their employees. Furthermore, employees were quite aware of the health and safety requirements in place and were actively involved in the health and safety matters.

From the empirical and field data, it is recommended that regulators of the building industry would have to develop an institutional health and safety framework in line with the constitution and the Labour Act of Ghana that would be stringently implemented in Ghanaian construction sites. More so, like international construction sites where supervisors insisted on health and safety measures, local constructions sites should also (put in more measures to) insist on such measures. Practitioners in the building industry should comply with all applicable Health, Safety and environment laws, regulations and standards in the various locations in which they operate. all management and supervisory staff should be made accountable for Health, safety and environment activities that affect personnel and the environment. Safe plant and equipment should also be provided for work activities

\section{References}

Armstrong, M. (2007). Human resource management practice (10 th ed.). London: Kogan Page Ltd.

Benjamin O. Alli; (2008), Fundamental principles of occupational health and safety / International Labour Office Geneva: ILO,

Casio, W. F. (1995). Managing human resources: productivity, quality of work life, profit ( 4th ed.). New York: McGraw Hill.

Construction (Design and Management) Regulations 2007 (CDM 2007) Available from: http://www.hse.gov.uk/construction/cdm.htm

Hämäläinen, Takala and Saarela (2006), Global Estimates of Occupational Accidents. Safety Science, 44, 137 - 156

Hair, J. F., Anderson, R., Tatham, R. and Black, W. (2010). Multivariate Data Analysis, Prentice Hall.

Kheni, Nongiba Alkanam (2008) Impact of health and safety management on safety performance of small and medium-sized construction businesses in Ghana, Unpublished PhD thesis, Department of Civil Engineering, Loughborough University, UK

Labour Department (2003) Annual Report, Labour Department, Accra, Ghana 
Hervie, D. M., \& Oduro-Nyarko, C. (2018). Managing Occupational Health And Safety In A Ghanaian Building Industry (A Case Study Of Some Construction Sites Of Eris Property Group In Accra). Advances in Social Sciences Research Journal, 5(9) 351-360.

Laryea, S. (2010) Health and safety on construction sites in Ghana. In: The Construction, Building and Real Estate Research Conference of the Royal Institution of Chartered surveyors, 2-3 September 2010, Dauphine Université, P aris, France.

Megginson, L., Byrd, M. L., \& Megginson, L. C. (2000). Small business management (an entrepreneur's guide book). New York: McGraw-Hill Companies.

Mugenda, G.,\& Mugenda, V. (2003). Research Methods. Nairobi: Acts Press. PNDC Law 187: Workman compensation law. 